\title{
Esclerodermia em placa: Relato de caso
}

\author{
Plaque scleroderma: Case report \\ Luísa Fernandes Rivelli Cardoso ${ }^{\dagger *}$, Maria Olívia de Lima Bezerra ${ }^{\dagger}$, Márcia Cristina Almeida Soares \\ Isabela Martins Moreira ${ }^{\dagger}$, Isabela Fernandes Rivelli Cardoso ${ }^{\ddagger}$, Ignez dos Santos Muri Mendonça ${ }^{\dagger}$
}

\begin{abstract}
Resumo
A esclerodermia é uma doença de etiologia desconhecida, que envolve o tecido conjuntivo e se caracteriza por endurecimento da pele devido à fibrose. Divide-se em esclerodermia sistêmica e localizada (morfeia). A morfeia clinicamente se subdivide em 5 formas: em placas ou circunscrita; em gotas; linear ou em golpe de sabre; disseminada ou generalizada e profunda. Com o objetivo de demonstração clínica, relata-se o caso de uma criança que apresentava esclerodermia localizada do subtipo em placa. Pela raridade dessa patologia relatos de caso da doença são importantes para orientar clínicos e dermatologistas para a suspeita diagnóstica, além de contribuir com a literatura científica. Diante disso, relata-se o caso de uma criança que apresentou morfeia em placa, com evolução clássica da doença. Foi iniciado tratamento com propionato de clobetasol $0,05 \%$, com melhora significativa das lesões dermatológicas, apresentando atualmente apenas hipercromia e atrofia residual.

Palavras-chave: Esclerodermia localizada; Morfeia, Criança; Doenças da pele; Tecido conjuntivo.
\end{abstract}

Como citar esse artigo Cardoso LFR, Bezerra MOL, Soares MCA, Moreira IM, Cardoso IFR, Mendonça ISM. Esclerodermia em placa: Relato de caso. Revista de Saúde. 2017 Jan./Jun.; 08 (1): 41-45

\begin{abstract}
Scleroderma is a disease of unknown etiology, involving the connective tissue and is characterized by induration of the skin due to fibrosis. It is divided into systemic and localized (morphea) scleroderma. Clinically, morphea is divided into 5 subtypes: plaque or circumscribed; bullous; linear or 'en coup de saber' (LSCs); generalized and deep morphea. In order to demonstrate the clinical characteristics of the disease, the case of a child who presented localized scleroderma (subtype plaque) is reported. Due to the rarity of this pathology, case reports are important to guide physicians and dermatologists towards clinical diagnosis, while contributing to scientific literature. The case presented describes plaque morphea with classic disease progression. Therapy with clobetasol propionate ointment $0.05 \%$ was initiated resulting in significant improvement of dermatological lesions. Currently, only hyperchromia and residual atrophy can be noticed.

Keywords: Scleroderma, Localized; Morphea; Child; Skin Diseases; Connective Tissue
\end{abstract}

O termo esclerodermia é proveniente do latim (skleros e derma), significando esclerosante ou endurecimento e pele, tratando-se de uma doença autoimune do tecido conjuntivo, de etiologia desconhecida, de evolução longa, tendo como característica clínica fundamental o endurecimento da pele devido à fibrose ${ }^{1,2}$.

Divide-se em esclerodermia localizada (EL) (morfeia) e esclerodermia sistêmica (ES). A forma localizada, diferentemente da sistêmica, caracterizase pelo envolvimento predominantemente cutâneo, mas com possibilidade de acometimento ocasional dos músculos subjacentes, ao passo que os órgãos internos, geralmente, são poupados. Esse tipo da doença afeta mais comumente as crianças ${ }^{1,3}$. Na ES, entidade mais comumente encontrada em adultos, há fibrose cutânea e acometimento de órgãos internos, originados por anormalidades estruturais e funcionais do endotélio e ativação do sistema imune, o que resulta em insuficiência renal, doença pulmonar intersticial, hipertensão arterial pulmonar, dentre outros. As alterações histológicas cutâneas são semelhantes, nas formas localizada e sistêmica ${ }^{1,4}$.

A transição da EL para ES é possível, porém rara, com taxas entre $0,9 \%$ e $5,7 \%{ }^{3}$.

A incidência da doença é de 2,7 para cada cem mil indivíduos, sendo mais prevalente no sexo feminino, havendo uma relação homem:mulher de 1:2 a $3^{5}$.

A etiologia da esclerodermia é desconhecida. Diversas hipóteses foram formuladas incluindo infecções virais e bacterianas, como infecção viral por Epstein-Barr, e infecção bacteriana por Borrelia

Afiliação dos autores: $\uparrow$ Universidade Severino Sombra

\$ Centro Universitário de Volta Redonda

*luisa_rivelli@hotmail.com 
burgdorferi, alterações nos receptores vasculares e na síntese do colágeno. $\mathrm{O}$ mais aceito atualmente é a associação de alterações vasculares e do metabolismo do colágeno associados à disfunção autoimune, fatores genéticos e eventualmente exógenos. Observaram-se lesões da esclerodermia localizada após traumatismo local, vacinação, procedimentos cirúrgicos e varicela, a partir disso, foi questionado se agressões de diversas naturezas poderiam liberar mediadores inflamatórios e citocinas, induzindo fibrose nesse subtipo da doença ${ }^{3,6}$. Pela relativa raridade da esclerodermia localizada, relatos de casos da doença são importantes para orientar clínicos e dermatologistas para a suspeita diagnóstica, além de contribuir com a literatura nacional, sobretudo na forma clínica - esclerodermia em placa, sobre a qual foram encontrados poucos artigos relacionados.

Diante disso, se objetiva relatar o caso de uma criança que apresentava esclerodermia localizada do subtipo em placa, com evolução clássica da doença.

A paceinte, natural e residente de Vassouras, RJ, feminina, parda, 13 anos, veio ao ambulatório de dermatologia do Hospital Universitário Sul Fluminense (HUSF), com relato de que há 3 anos surgiu uma lesão hipercrômica, endurecida, bem delimitada, arredondada de aproximadamente $2 \mathrm{~cm}$ de diâmetro na região ânterosuperior da coxa esquerda, sem outras alterações. No decorrer de aproximadamente dois anos de evolução da doença houve aumento da extensão da lesão até cerca de $20 \mathrm{~cm}$. A paciente nagava a existência de sinais sistêmicos.

Nessa fase da doença, a paciente apresentava lesão atrófica na região ântero-superior da coxa esquerda, em placa bem delimitada, hipercrômica, de centro acastanhado, envolta por anel violáceo denominado lilac ring (Figura 1), de superfície lisa e brilhante, endurecida, de difícil pregueamento, anidrótica e alopécica. A paciente relatou eventual prurido associado.

Houve progressão da lesão com aparecimento também na perna esquerda, preservando as mesmas características, o que foi precedido por um trauma nesta região (Figura 2), momento em que a paciente procurou atendimento no HUSF. A hipótese clínica foi de esclerodermia localizada, subtipo em placa. Foram solicitados exames para anticorpo anti-centrômero e anticorpo anti-RNA polimerase 1, ambos com resultados negativos.

Foi solicitada a biópsia da borda ativa da lesão, o que evidenciou esclerose da derme, com pequeno infiltrado inflamatório linfocitário ao redor dos vasos sanguíneos (Figura 3) e na junção da derme esclerótica com o tecido subcutâneo (Figura 4), além de estruturas

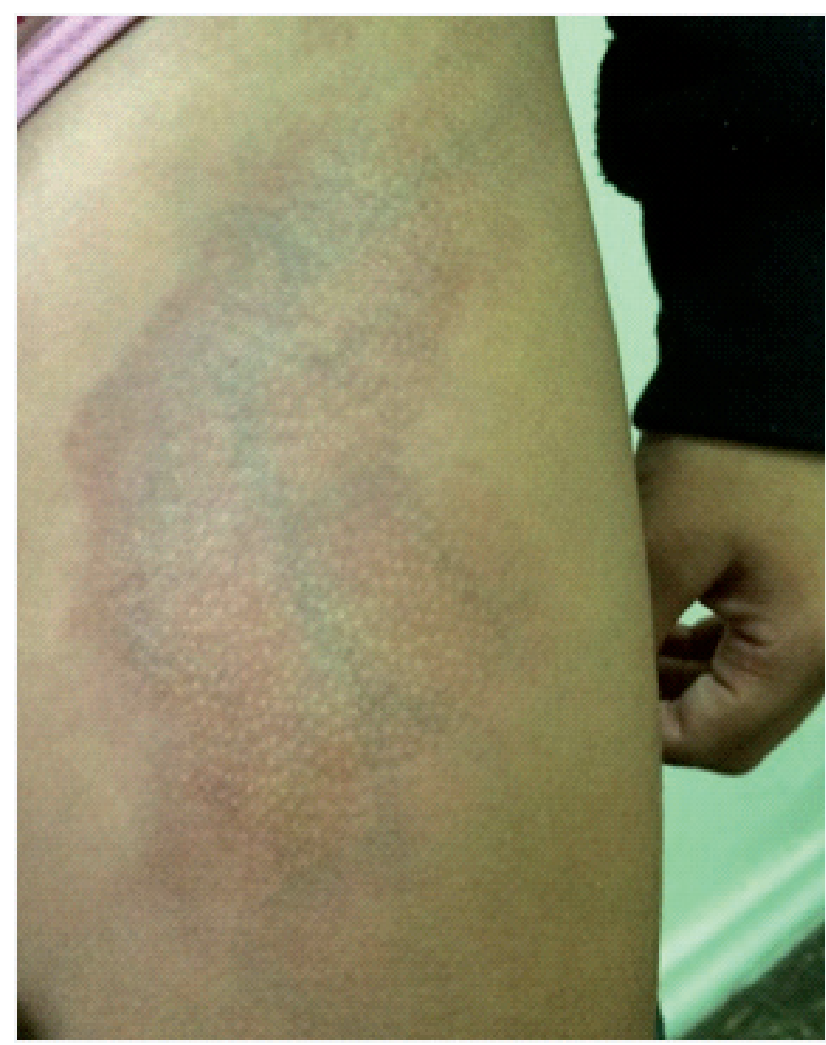

Figura 1. Foto cedida pela paciente. Região ântero-superior da coxa esquerda onde fica evidente placa bem delimitada, hipercrômica, de centro acastanhado, envolta por anel violácio denominado lilac ring. 

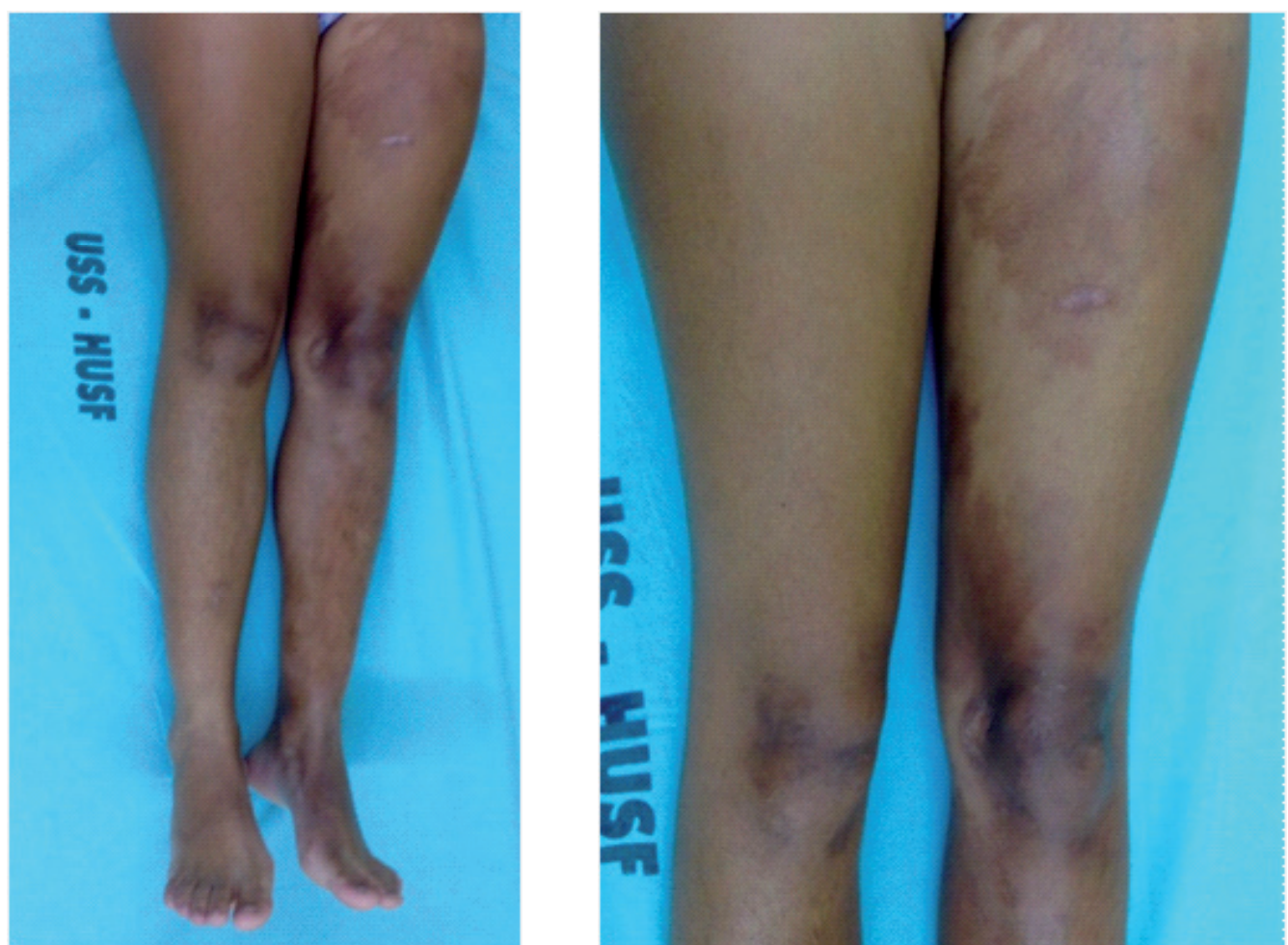

Figura 2: Placa esclerótica em coxa e perna esquerda (setas). Fonte:Próprios autores.

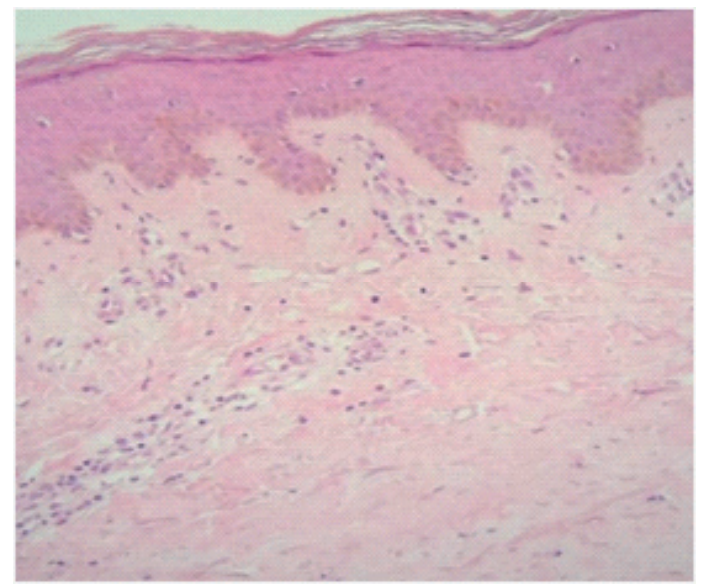

Figura 3. Pele - Esclerose da derme com pequeno infiltrado inflamatório linfocitário ao redor dos vasos sanguíneos. Coloração HE, magnificação 400x. Fonte: Próprios autores

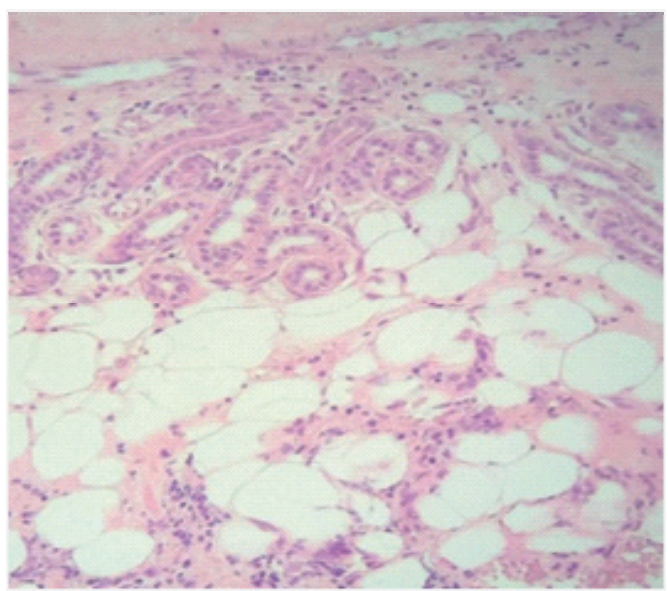

Figura 4. Pele - Infiltrado inflamatório na junção da derme esclerótica com o tecido sub-cutâneo. Coloração HE, magnificação 400x. Fonte: Próprios autores.

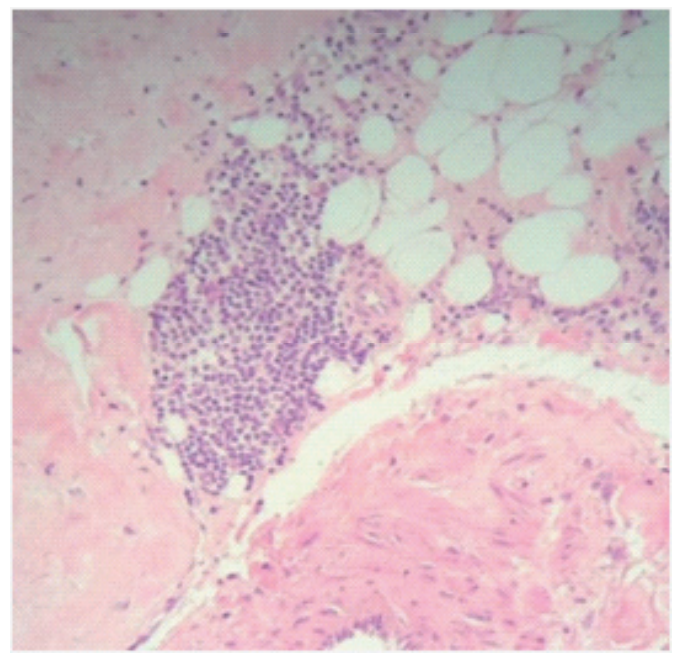

Figura 5. Estruturas anexiais envolvidas pela esclerose. Redução do tecido adiposo peri-anexial. Coloração HE, magnificação 400x. Fonte: Próprios autores 
anexiais envolvidas pela esclerose (figura 5), confirmando a hipótese de esclerodermia localizada.

Foi iniciado o tratamento com proprionato de clobetasol $0,05 \%$ duas vezes ao dia, com melhora significativa do quadro, havendo estabilização e involução relativa da doença com o tratamento proposto. No momento da redação deste artigo, após um ano do início da terapia, ficava evidente apenas hipercromia e atrofia residual. A paciente se encontrava ainda em acompanhamento ambulatorial para avaliação do quadro, com bom prognóstico e tendência à involução. A esclerodermia localizada clinicamente se subdivide em 5 formas: morfeia em placas ou circunscrita, morfeia em gotas, linear ou em golpe de sabre, disseminada ou generalizada e profunda ${ }^{7}$.

O subtipo em placas, é a apresentação clínica mais frequente na população geral. Ocorre principalmente no tronco, podendo envolver couro cabeludo e membros, como relatado no caso acima. Esta forma clínica, caracteriza-se por placas redondas ou ovais, com 2 a $15 \mathrm{~cm}$ de diâmetro, de bordas irregulares, enduradas, superfície lisa, cor marfínica, que na fase ativa estão envolvidas por halo eritemato-violáceo, conhecido como anel lilás (lilac ring) ${ }^{6}$.

O diagnóstico da esclerodermia localizada é feito basicamente pelo exame físico, onde são observadas as características da lesão, como foi visto na paciente descrita. Anormalidades laboratoriais também podem ser encontradas, como elevados títulos de auto anticorpos que se correlacionam com a severidade da doença, incluindo anticorpos antinúcleo, anti-ssDNA e anti-histona (AAH). Autoanticorpos mais específicos, como anti-SCL-70, anti-centrômero, anticorpos antiRo/SSA e anti-La/SSB e anti-U1-RNP, podem preceder o desenvolvimento de doença sistêmica ${ }^{3}$.

Após a observação da lesão dermatológica sugestiva de morfeia em placa no caso relatado, foi solicitada a pesquisa de anticorpos, dentre eles o anticorpo anti-centrômero, com a finalidade excluir um possível acometimento sistêmico. Os resultados foram negativos, o que corroborou o diagnóstico de esclerodermia localizada. Além disso, não foram observadas alterações descritas na literatura como: eosinofilia, condiçãoque frequentemente se correlaciona com a extensão da doença, e hipergamaglobulinemia, com elevações policlonais de IgM e IgG, que ocorrem em cerca de $50 \%$ dos pacientes com doença cutânea grave e são mais comuns durante a progressão clínica ${ }^{3}$. A ausência desses achados pode ser justificada pela solicitação desses exames numa fase tardia da doença, quando a paciente procurou atendimento médico.

Apesar da literatura relatar que achados ultrassonográficos podem ser úteis, já que permitem associar o aumento da espessura e a redução da ecogenicidade da derme com a fase inflamatória da doença $^{12}$, o exame ultrassonográfico não foi solicitado para elucidação diagnóstica no caso mencionado, pois apesar de ser um método não invasivo, é operador dependente e ainda não há grandes estudos que comprovem sua eficácia. Além de permitir quantificar a espessura da derme, essa informação pode ser usada no controle pós-tratamento, associada à avaliação clínica.

Outras técnicas que têm potencial para fornecer informações são a fluxometria por laser Doppler e a imagem por laser Doppler ${ }^{3}$, porém tais técnicas são ainda pouco disponíveis em alguns hospitais e não acrescentavam benefício ao caso em questão, já que o diagnóstico de esclerodermia em placa já estava bem estabelecido.

O prognóstico da esclerodermia localizada é favorável, sendo rara a evolução para a forma sistêmica; as lesões da morfeia podem involuir em 3 a 5 anos deixando hiperpigmentação e atrofia residual, como ocorreu nesta paciente, porém em casos mais graves permanecem lesões atróficas deformantes e, eventualmente, anquilosantes ${ }^{2,6}$.

Para diagnóstico diferencial da esclerodermia, deve se excluir sempre o uso de substâncias químicas que podem induzir à fibrose como bleomicina, isoniazida, nitrofurantoina, hidantoina, valproato de sódio e vitamina K (após injeção), bem como investigar a exposição ao cloreto polivinil, sílica e resinas epóxi, que podem gerar síndromes esclerodermiformes, muito semelhantes à esclerodermia ${ }^{7,11}$. Além disso, o diagnóstico diferencial também se faz com hanseníase, algumas formas de porfiria, escleromixedema e o quadro denominado stiff skin syndrome, o qual apresenta endurecimento da pele com limitação da mobilidade articular e geralmente acontece no primeiro ano de vida ${ }^{7}$.

Devido à etiologia desconhecida, nenhum tratamento específico para a esclerodermia está disponível. O objetivo da terapia é reduzir velocidade de progressão da doença, de modo a prevenir o desenvolvimento de complicações funcionais e estéticas. Dessa forma, a terapêutica desta patologia atua no componente inflamatório, na liberação de citocina e na deposição do colágeno ${ }^{3,5}$.

A fisioterapia tem grande importância no tratamento da esclerodermia localizada, especialmente em pacientes com contraturas e limitações dos movimentos, o que não ocorreu na história clínica relatada $^{13}$.A fototerapia com psolareno eluzultravioleta também tem se mostrado satisfatória no tratamento da esclerodermia. O uso de D-penicilamina, tacrolimus tópico sob oclusão, calcitriol oral, calcipotriene tópico, metotrexato isoladamente ou combinado com pulso de corticoide, imiquimode tópico, tretinoína tópica com lactato de amônio e ácido antralínico, têm demonstrado sucesso no tratamento dessa patologia ${ }^{5}$. A terapia sistêmica mais comumente utilizado é o metotrexato (MTX) em conjunto com corticosteroides. 
Especialmente em crianças, o MTX tem sido o recurso mais regularmente utilizado nos últimos anos ${ }^{3}$.

No caso de lesões únicas em placa, os pacientes devem ser informados do caráter benigno e geralmente autolimitante da doença. Podem-se usar esteroides tópicos ou oclusivos para aumentar a absorção. Se a lesão aumenta rapidamente ou envolve áreas funcionalmente importantes, a terapia sistêmica deve ser indicada. Nesses casos, corticosteroides orais são a primeira escolha, com respostas variáveis descritas com o uso da droga ${ }^{3}$. No caso clínico mencionado, a escolha do tratamento com propionato de clobetasol $0,05 \%$ foi feita devido a boa aceitação desse medicamento, que tem como mecanismo de ação o controle das lesões inflamatórias da pele e alívio do prurido, quando presente.

Houve estabilização e involução relativa da doença com o tratamento proposto, havendo após um ano de tratamento, hipercromia e atrofia residual. A paciente se encontrava em acompanhamento ambulatorial para avaliação do quadro, com bom prognóstico e tendência à involução progressiva.

\section{Referências}

1. Torok KS. Pediatric scleroderma: systemic or localized forms. Rev Pediatr Clin North Am. 2012; 59(2):381-405.

2. Azulay RD, Azulay DR, Abulafia LA. Azulay dermatologia. $6^{\text {nd }}$ ed. Rio de Janeiro: Guanabara; 2015.

3. Zancanaro PC, Isaac AR, Garcia LT, Costa, IM. Esclerodermia localizada na criança: aspectos clínicos, diagnósticos e terapêuticos. An Bras Dermatol. 2009; 84(2):61-172.

4. Tomiyoshi C. Case for diagnosis. An Bras Dermatol. 2010; 85(3):397399.

5. Wolff K, Goldsmith AL, Katz IS, Gilchrest AB, Paller SA, Leffell JD. Tratado de dermatologia Fitzpatrick. $7^{\text {nd }}$ ed. Vol II. São Paulo: Revinter; 2011 .

6 Sampaio PAS, Rivitti AE. Dermatologia. $3^{\text {rd }}$ ed. São Paulo: Artes médicas;2008.

7. Silva RM, Castro RCM. Fundamentos de dermatologia. $2^{\text {nd }}$ ed. Rio de Janeiro: Atheneu; 2010.

8. Paula RA, Ribeiro BN, Bahia PR, Ribeiro RN, Carvalho LB. ParryRomberg syndrome: findings in advanced magnetic resonance imaging sequences-case report.Rev Radiol Bras. 2014; 47(3):186-188.

9. Careta MF, Romiti R. Localized scleroderma: clinical spectrum and therapeutic update. An Bras Dermatol. 2015; 90(1):62-73.

10. Zanini M. Atrofodermia de Pasini e Pierini. Rev Med Cutan Iber Lat Am. 2013; 41(5):242.

11.Leroux MBA. Esclerodermia localizada: Diagnósticos diferenciales. Revargent Dermatol. 2011;92(3):185-300.

12. Bouer M. Correlação clínica e ultra-sonográfica na esclerodermia localizada cutânea. Rev Radiol Bras. 2008; 41(2):87-91.

13. Bortolini J, Birick MT, Magda C. Atuação Fisioterapêutica na Esclerodermia: Um Estudo de Caso. Rev Cont \& Sa. 2013;03(4):111-112. 